\title{
An Infantile Case of Subacute Sclerosing Panencephalitis with an Abnormal Ganglioside Pattern in the Brain
}

\author{
A. D. DAYAN ${ }^{\star}$ AND J. N. CUMINGS \\ From the Department of Pathology and Wessex Neurological Centre, \\ General Hospital, Southampton, and Institute of Neurology, London
}

Recent evidence has suggested that subacute sclerosing panencephalitis (SSPE) is due to temperate infection of the brain by a virus, probably measles virus (Symposium, 1968). In the majority of patients with SSPE, chemical analysis of the brain has shown features of inflammation and demyelination (Cumings, 1965), though 2 patients have been described previously whose brains had abnormal patterns of gangliosides (Norton, Poduslo, and Suzuki, 1966; Ledeen, Salsman, and Cabrera, 1968).

An infant is described in this paper, the youngest reported case of SSPE, in whom the histological features of the encephalitis at necropsy were studied by light and electron microscopy, and in whom chemical analysis of the brain showed an unusual pattern of gangliosides.

\section{Case Report}

A male infant, the first child of healthy, unrelated English parents, was delivered at full term after an uneventful pregnancy, and appeared to develop normally for the first 2 months of life. His mother, aged 28 years, said she had had measles 'as a small child', and was not known to have been in contact with this or any other infectious disease during pregnancy. Both parents and the baby lived in a small rural community and were not known to have been exposed to any such disease during the child's life. The family's pet dog seemed healthy throughout this period.

At 2 months the child began to dribble excessively, and was seen to have occasional attacks of twitching of the right side of the face. These continued until he was 4 months old, when he began to have grand mal convulsions, with more marked jerking of the right side of the body. The major fits lasted for 2 to 3 hours and occurred 2 or 3 times daily despite symptomatic treatment with anticonvulsants. In between

Received September 3, 1968.

* Present address: Department of Neuropathology, The Hospital or Sick Children, London W.C.1. attacks he was a floppy, miserable baby of normal bodily habitus without any localizing signs of neurological damage. His general condition deteriorated rapidly, and he died of bronchopneumonia at the age of 5 months.

Investigations. $\mathrm{Hb} 9.9$ g./100 ml.; WBC 7600/ cu.mm.; $27 \%$ polymorphs and $69 \%$ lymphocytes; $\mathrm{CSF}$ at 4 months-cells $48 \mathrm{lymphocytes/cu.mm.;} \mathrm{protein}$ $40 \mathrm{mg}$. $/ 100 \mathrm{ml}$.; no organisms were grown on routine bacteriological culture.

Electroencephalogram. Periodic sharp wave complexes on both sides, but more marked on the right, suggested a generalized degenerative disorder (Fig. 1). The appearances were compatible with the diagnosis of SSPE.

Necropsy findings. Macroscopically, apart from bronchopneumonia, the viscera and endocrine glands appeared normal. The spleen $(20$ g.) had prominent Malpighian bodies on its cut surface, the thymus (19 g.) appeared normal, and lymph nodes generally were small.

Microscopical examination did not show any abnormality in viscera and endocrine glands. The thymus was partly involuted. The spleen and lymph nodes appeared normal and did not contain reaction centres. There was a moderate number of plasma cells in the spleen and bone-marrow. Giant multinucleate cells and intracellular inclusion bodies were not found anywhere. Frozen sections of large and small intestine, liver, spleen, and kidney were stained by periodic acid-Schiff, Sudan black, Baker's acid haematein, and Kulschitsky's haematoxylin methods. No abnormal lipid material was found in neurones of the myenteric plexus or in cells of the reticuloendothelial system.

On naked-eye examination, the brain (weight $760 \mathrm{~g}$. after fixation) appeared atrophic, and the cerebellum was shrunken. On coronal slicing of the cerebrum the cortex of the parietal and temporal lobes was thin, and most of the centrum ovale including subcortical Ufibres appeared grey. In the temporal lobes in particular the white matter had a gelatinous grey appearance 


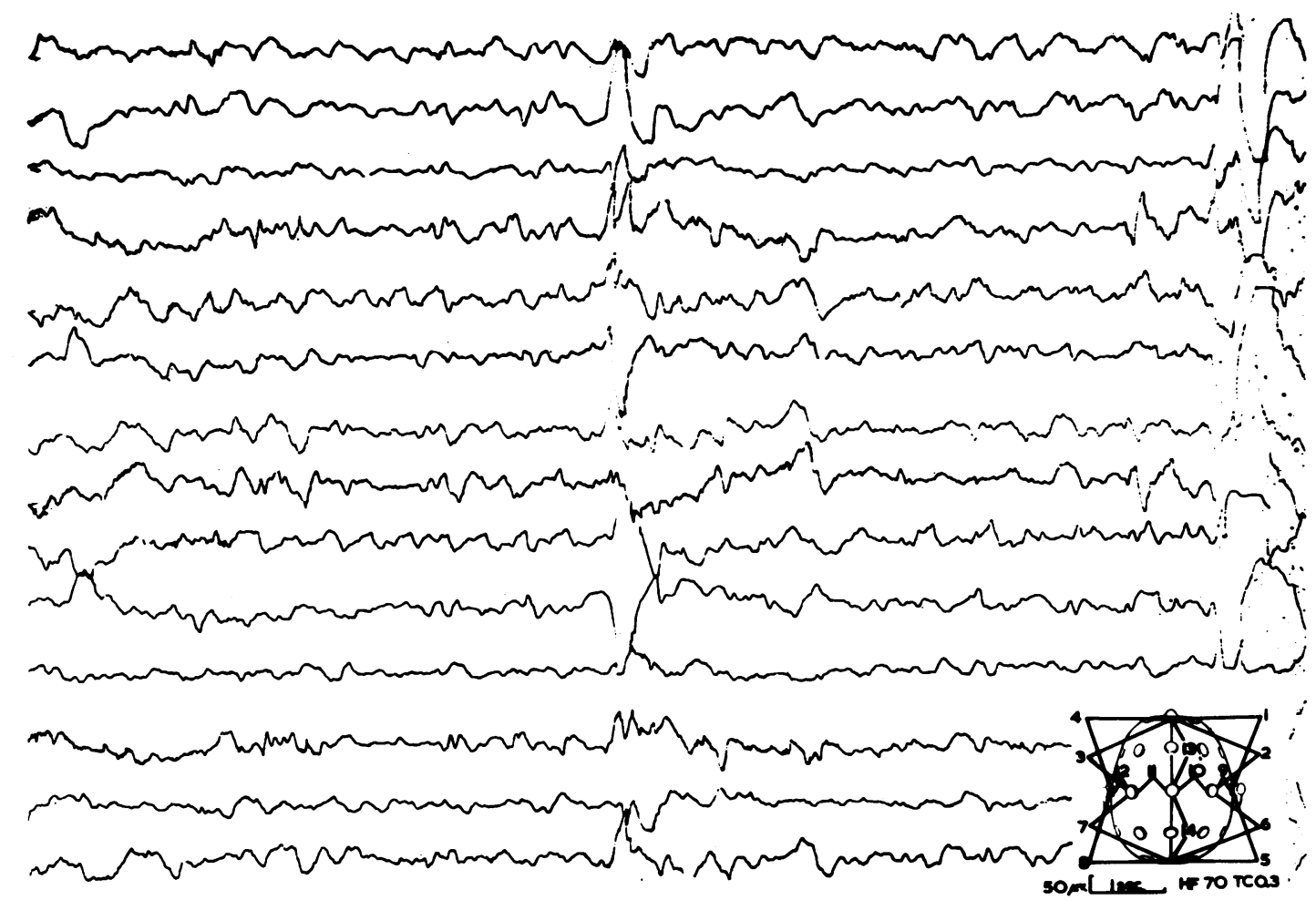

FIG. 1.-Periodic complexes in EEG.

and contained small cavities. There was moderate dilatation of the lateral ventricles. The basal ganglia and brain-stem appeared normal. Folia of the cerebellum were generally shrunken and the white matter was unusually grey coloured. The spinal cord appeared normal.

Microscopical findings. Throughout all layers of the cerebral cortex there was an active subacute encephalitis which was more marked in the parietal and particularly in the temporal lobes and opercula of the insula, where there was a devastating loss of neurones (Fig. 2). There were fewer lesions in the occipital and frontal cortex. In affected areas neurones were damaged or had disappeared, and there was gliosis and many active microglia and compound granular corpuscles (Fig. 3). In less affected areas, such as the calcarine and frontal cortex, lesions were restricted to occasional foci of inflammatory cells and degenerating neurones. Small blood vessels in grey and white matter were cuffed by lymphocytes, plasma cells, and other mononuclear cells with pyroninophilic cytoplasm. Similar active lesions of moderate intensity were present in the basal ganglia and thalamus. In the centrum ovale there was widespread gliosis, with many binucleate and gemistocytic astrocytes and thick sleeves of chronic inflammatory cells around blood vessels. The grey cavitated areas seen by naked eye in the temporal lobes were found to be extensive areas of destruction of myelin sheaths and axis cylinders in which only a loose meshwork of scar tissue remained (Fig. 4). Myelination had begun in the centrum ovale and internal capsule, and appeared somewhat deficient in the brain-stem and spinal cord.

There was diffuse gliosis of moderate intensity in both cerebral peduncles, in the pes pontis, and in the anterior part of the medulla. In the brain-stem active inflammatory lesions and perivascular cuffing was found in the corpora quadrigemina and adjacent cranial nerve nuclei. The cerebellum showed two main lesions. There was moderate demyelination and diffuse gliosis of its white matter and patchy radial gliosis of the cortex (Fig. 5). The majority of cerebellar folia appeared normal in Nissl-stained preparations though a few were distorted (Fig. 6). In such preparations, cells of the cortical layers also appeared normal, but in sections stained by Cajal's silver nitrate-pyridine method for the cerebellum, Purkinje cell dendrites were abnormal (Fig. 7). Instead of the usual regular inverted pyramidal pattern of branching, many cells appeared to have a single thick vertical bar-shaped dendrite, at the distal end of which was a fusiform or 


\section{Subacute Sclerosing Panencephalitis with Abnormal Ganglioside Pattern in Brain}

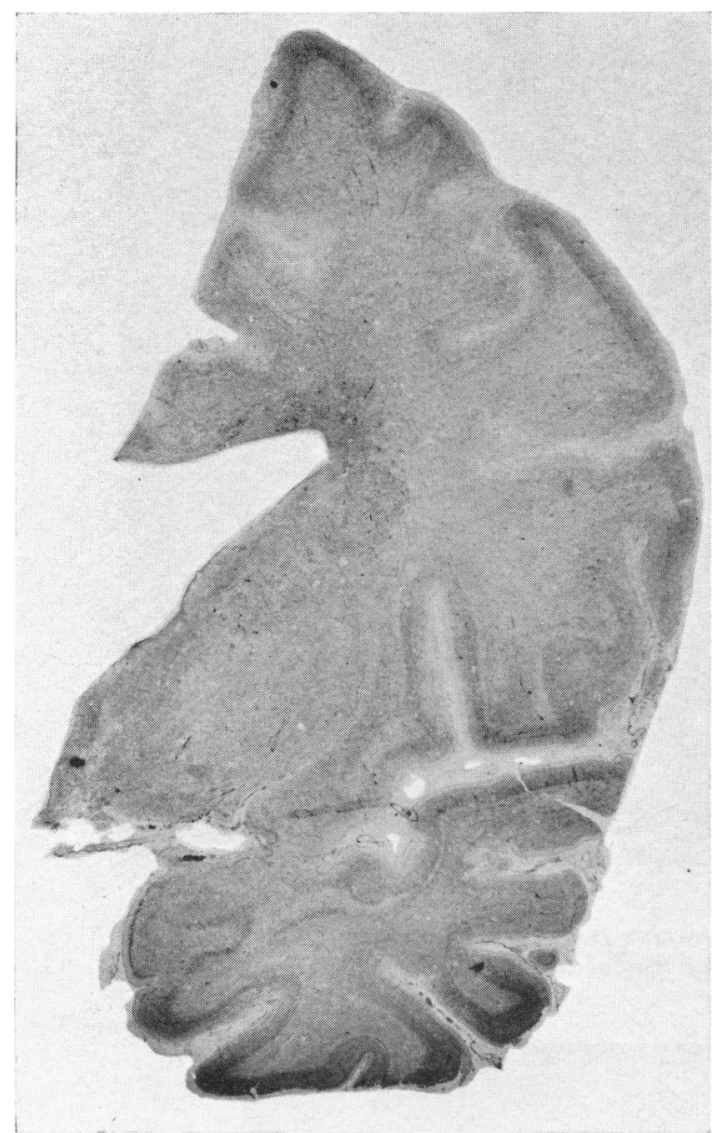

Fig. 2.-Extensive damage to cortex of insula and parietal and temporal lobes, and clouds of inflammatory cells around angle of lateral ventricle. (Nissl. $\times 1 \cdot 5$.)

club-like swelling from which arose radiating meshes of fine dendrites. No acute inflammatory lesions were found in the cerebellum.

In the spinal cord there was a small amount of gliosis in the anterior and lateral columns. The grey matter and posterior columns appeared normal. No lesions were seen in posterior root ganglia.

Inclusion bodies. In damaged areas in the cerebral cortex of the parietal and temporal lobes and in the thalamus, there were many rounded Cowdry type A intranuclear inclusions surrounded by a clear halo (Fig. 8). The distribution of inclusion bodies was patchy, as adjacent areas might contain from almost none to about 1 cell in 20 bearing an inclusion. They were seen in glial cells, both astrocytes and oligodendrocytes, and in neurones. Few inclusion bodies were found in cells in less severely damaged areas, and none were seen in any cells in the cerebellum. The inclusions appeared homogeneous and all were pyroninophilic by the Unna-Pappenheim methyl-green pyronin method, variably eosinophilic or amphophilic after haematoxylin and eosin, and bluish or unstained in Nissl preparations. Intracytoplasmic inclusions were not found.

Pexipheral nervous system. Random samples of voluntary muscles and major peripheral nerve trunks appeared normal. Teased, isolated fibres from a sural nerve had normal appearing myelin sheaths.

Histochemistry. Small amounts of material staining orange with Sudan III were present in macrophages in frozen sections of formol-fixed cerebral cortex and around a few blood vessels in the centrum ovale. No abnormal coloration was found of neurones or glial cells anywhere in frozen sections stained by the periodicacid Schiff, Baker's acid haematein, Kulschitsky's haematoxylin for myelin, alcian blue, Hirsch-Peiffer, and Feyrter's enclosure methods. In the white matter, these techniques showed only some myelinated fibres of normal appearances in less damaged areas.

Electron microscopy. Formol-fixed necropsy samples, the only material available, of the parietal cortex were post-fixed in osmic acid, embedded in Epon, and uranium and lead-stained sections examined in an AEI EM6 electron microscope.

Over-all preservation of the tissue was poor, and fine details of cellular structure could not be identified.

In many nuclei of parenchymal cells, probably glial in nature, there were intranuclear filaments about $180 \AA$ diameter (Fig. 9). At high magnifications, some filaments appeared to have a ribbed structure. Cells containing the intranuclear filaments were those which had intranuclear inclusions on light microscopy of the corresponding thick sections. Filaments or virus-like particles were not seen in the cytoplasm of any cells.

A portion of the parietal cortex was homogenized by sonication and centrifuged. Negatively stained preparations of the suspension were examined by electron microscopy (Fig. 10), and tangled filaments of about $180 \AA$ diameter were found which had a regular helical structure (Mrs. J. D. Almeida, 1967, personal communication).

The appearances found on electron microscopy were interpreted as being consistent with the RNA helix of a virus of the measles-canine distemper-rinderpest group.

Serology. The patient's serum was not available for examination.

Serum was obtained from his mother 9 months after the onset of the child's illness. It contained no detectable antimeasles antibody by a complement-fixing technique.

Chemical analysis. Portions of the frontal lobe of the brain, liver, and spleen frozen at necropsy were examined biochemically. White matter and cerebral cortex were separated and the water content of each determined separately by drying at $37^{\circ} \mathrm{C}$. in vacuo. 


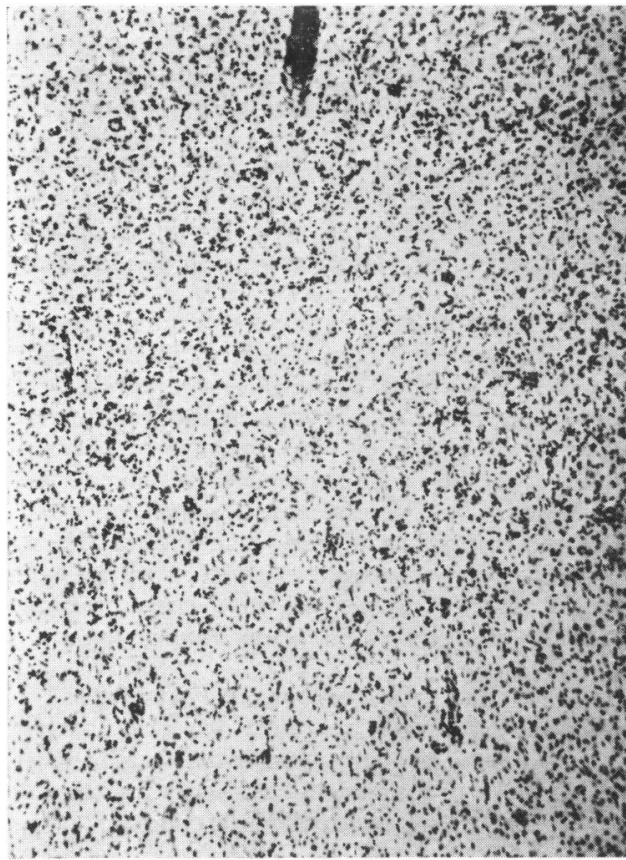

(a)

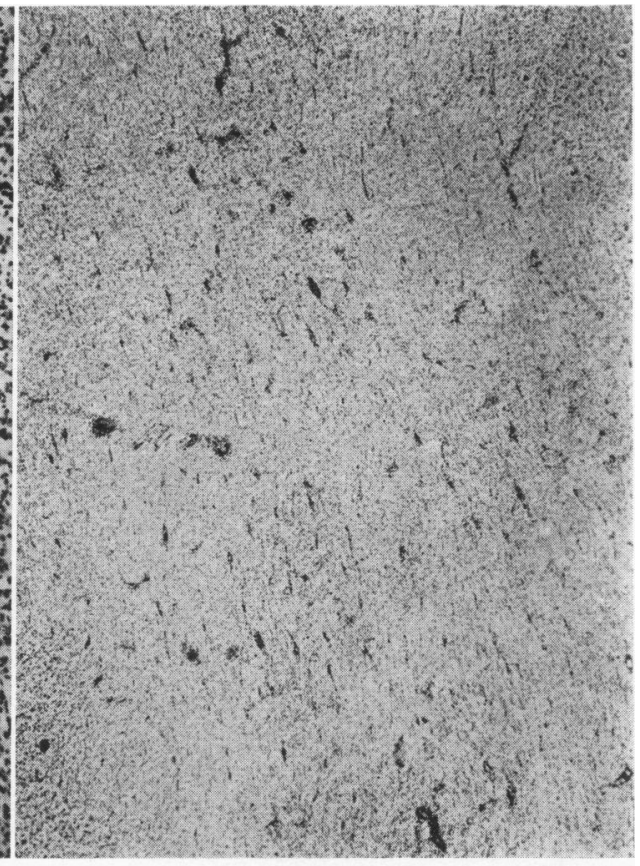

(b)

Fig. 3(a).-Diffuse inflammatory infiltration and loss of neurones from parietal cortex. (Nissl. $\times 63$.$) (b) Peri-$ vascular cuffing in white matter of frontal lobe. $($ Nissl. $\times 20$.

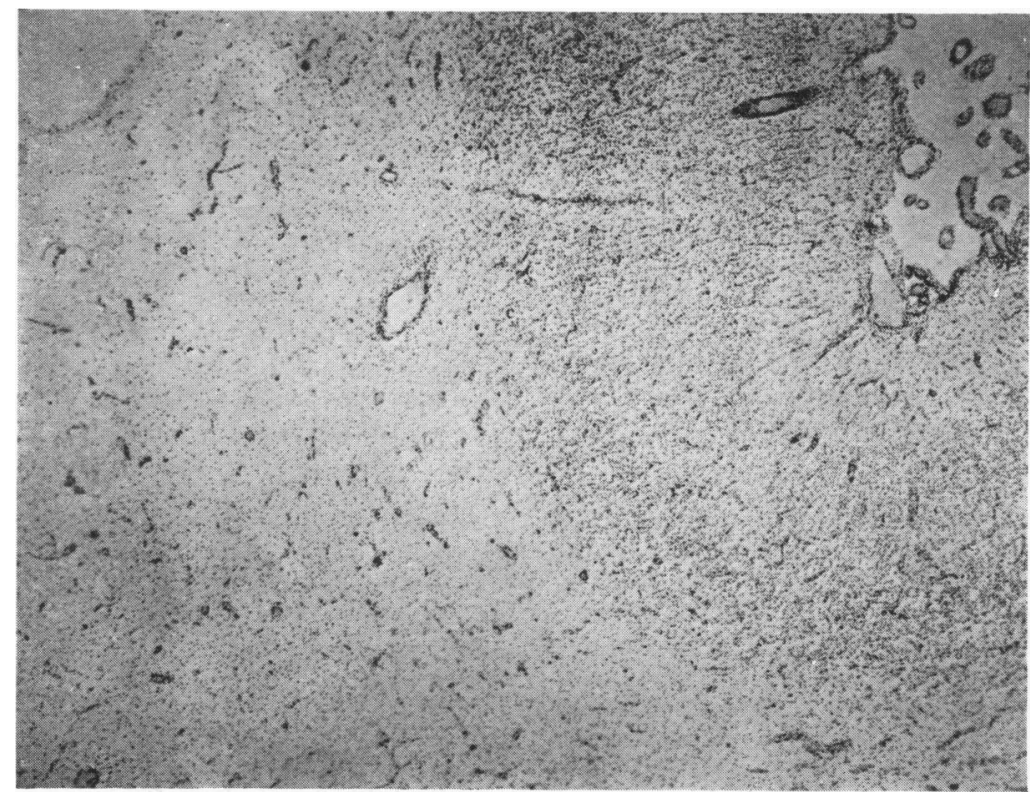

Fig. 4.-Devastating loss of neurones from temporal cortex, perivascular cuffing by inflammatory cells and severe damage to white matter. (Nissl. $\times 24$.) 


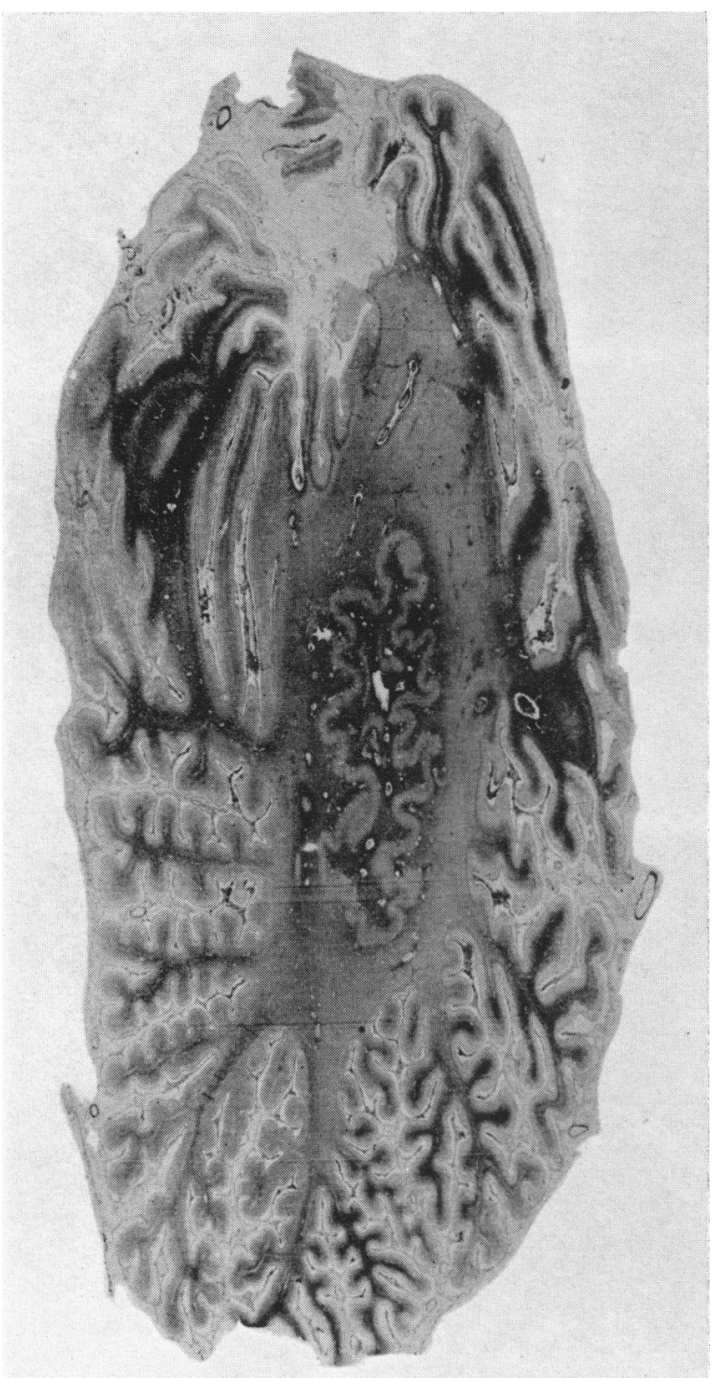

FIG. 5.-Diffuse gliosis of cerebellar white matter. (Holzer $\times 3 \cdot 8$.)

Lipid extracts of cerebral white matter and cortex, spleen, and liver were prepared by the technique of Folch, Lees, and Sloane Stanley (1957). The various lipids were estimated by the methods of Cumings and Rozdilsky (1965), except for total cerebroside which was determined by the techniques of Radin, Brown, and Lavin (1956), and Svennerholm (1956). Thin-layer chromatography (TLC) was carried out by the method of Müldner, Wherrett, and Cumings (1962).

The results obtained from the brain are shown in the Table, together with values from a normal child of the same age. Though there is some reduction of

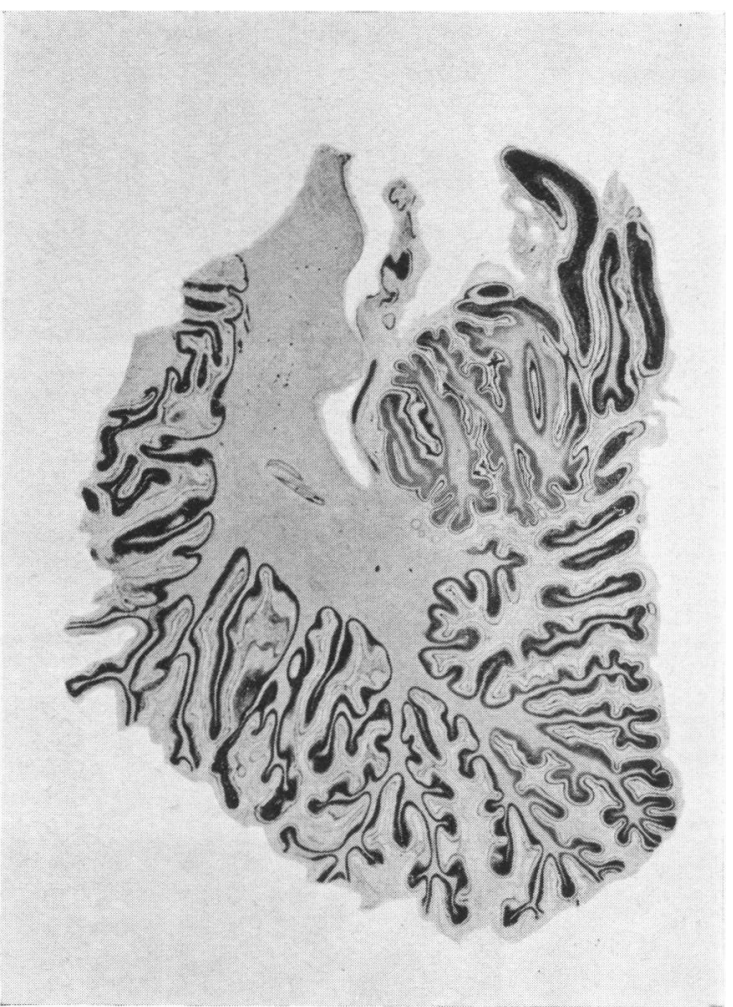

Fig. 6.-Irregularities of cerebellar folia. (Nissl. $\times 3$.

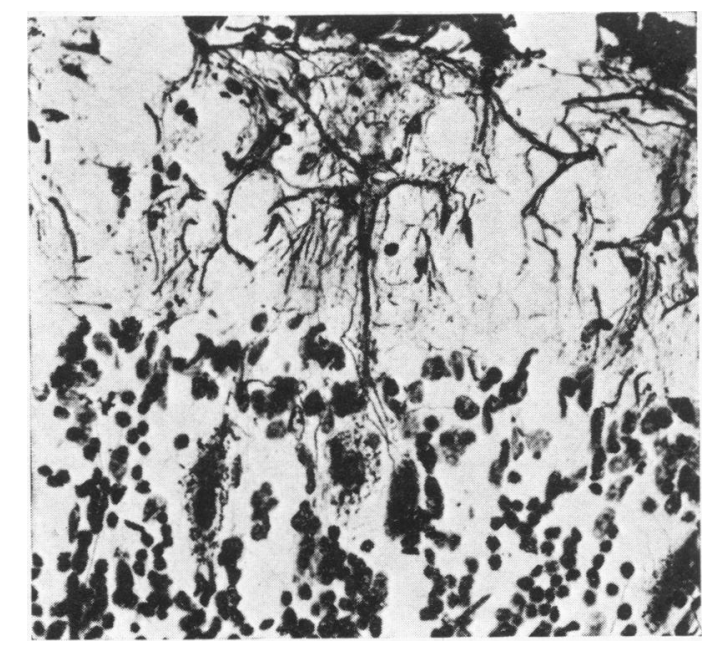

FIG. 7.-Abnormal club-like dendritic arborization of Purkinje cell. (Cajal's silver nitrate-pyridine. $\times 400$.) 

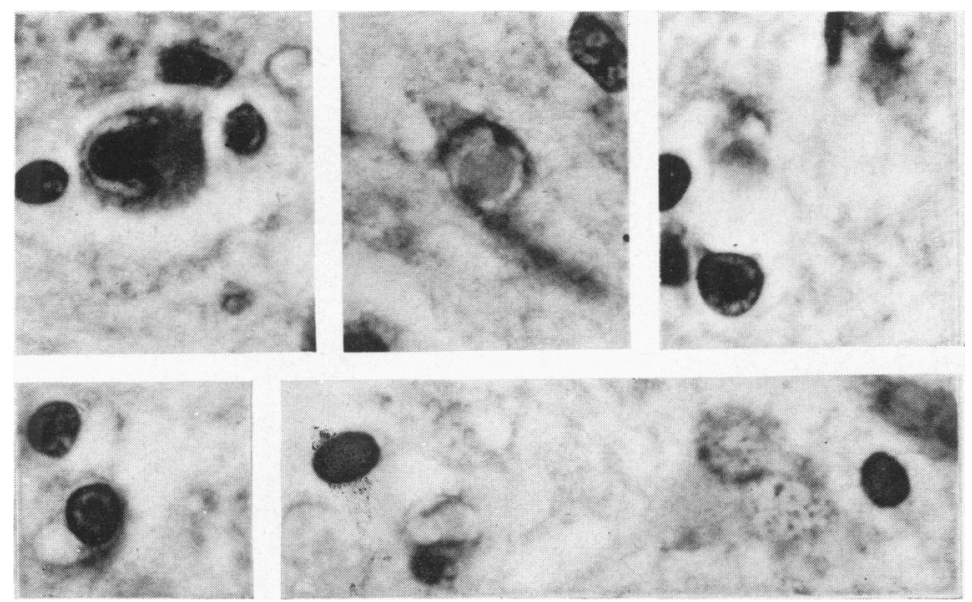

Fig. 8.-Intranuclear inclusion bodies in glial cells and neurones. (Haemalum and eosin. $\times 950$.)

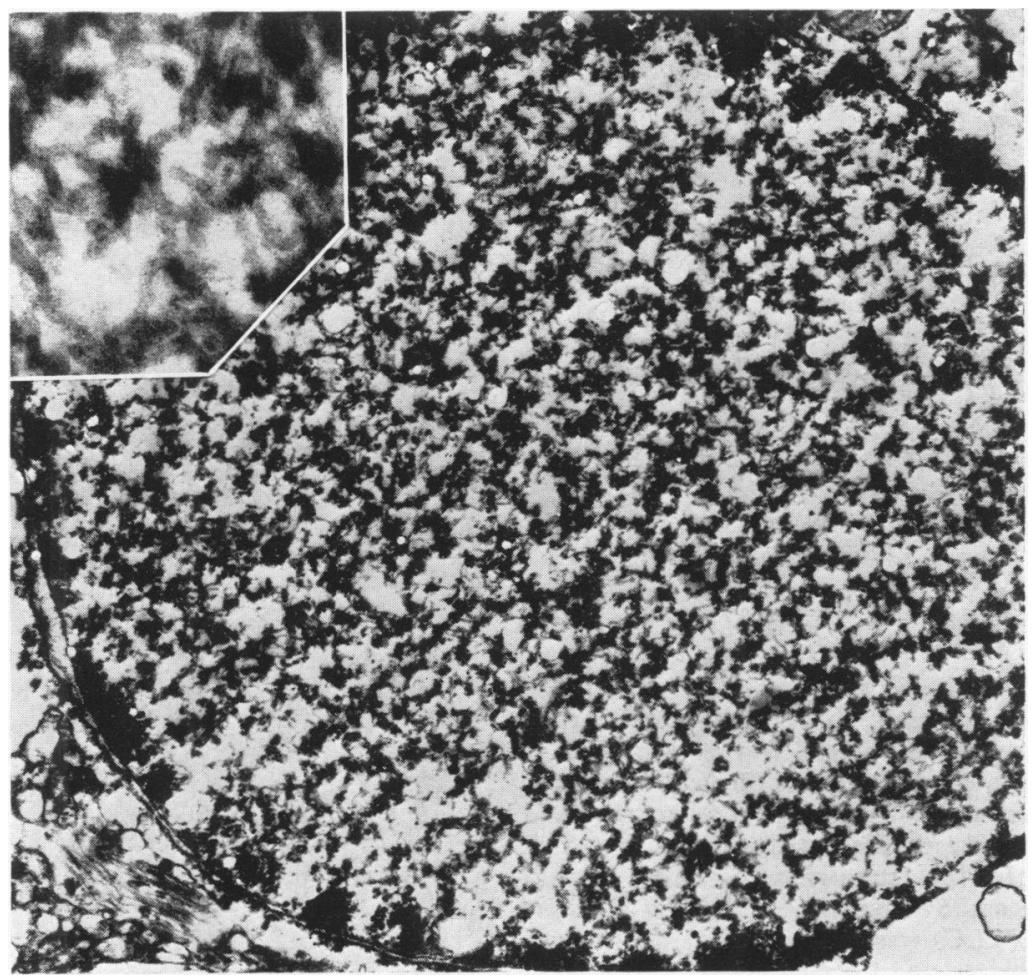

FIG. 9.-Electron micrograph of nucleus of unidentified cell in the brain, showing tangled mesh of virus-like particles. $(\times 12,800)$. Insert shows their filamentous structure. $(\times 80,000$. 


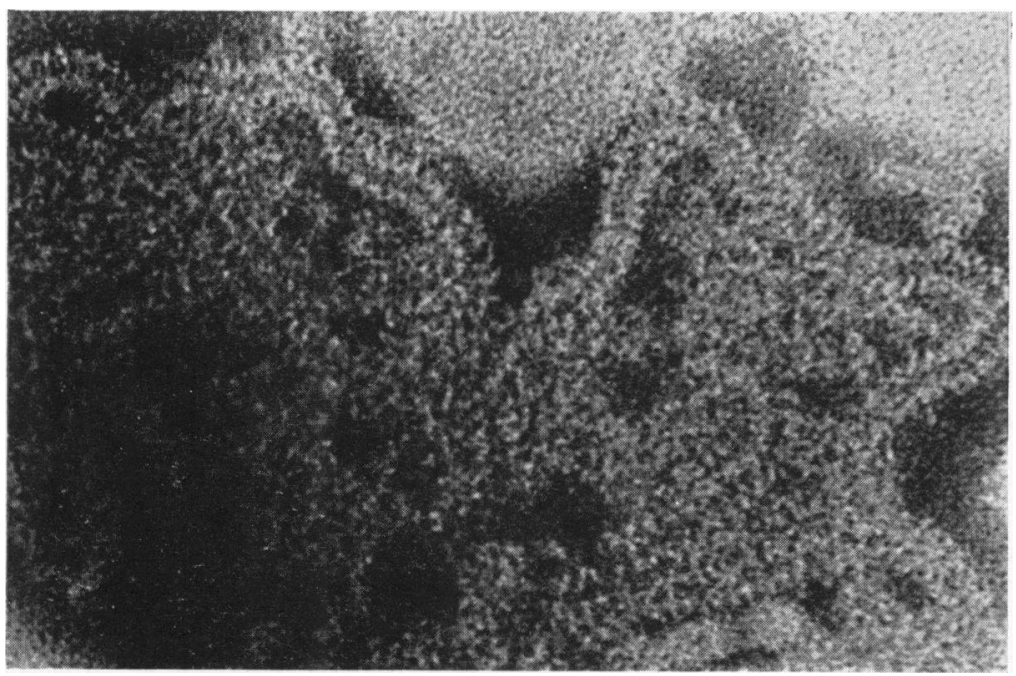

FIG. 10.-Compound helical structure of isolated virus-like filaments is seen in this negatively stained electron micrograph. $(\times 341,000$.

myelin lipids and a slight increase in esterified cholesterol, none of the findings suggest any specific disease. On TLC there was a normal pattern of phospholipid, cerebrosides, and sulphatides. The ganglioside pattern of both cortex and white matter was markedly abnormal (Fig. 11), as both showed prominent bands of the monosialo-compounds $G_{M 3}$ and $G_{M 4}$, which are rarely present in normal brain and then only in trace amounts.

A small sample of formalin-fixed ulnar nerve was subjected to the same lipid extraction and TLC techniques. A similar pattern of gangliosides was detected, though present in much smaller quantities.

\section{Discussion}

The morbid anatomical findings in the brain of the present patient were those of an inclusion body encephalitis. The nature and distribution of the lesions are compatible with the diagnosis of subacute sclerosing panencephalitis (SSPE) though more active than is commonly seen in this disorder (Greenfield, 1963; Symposium, 1968), and having an unusually severe effect on the temporal lobes (Osetowska, 1961). These differences may reflect the particular reactions of an immature brain to the pathological processes of a subacute encephalitis. The age of the child at the onset of the clinical disorder, 2 months, is far younger than

FIG. 11.-TLC of lipid extract from cerebral white matter and cortex of patient. The ganglioside bands $G_{M 3}$ and $G_{M 4}$ (Svennerholm's nomenclature) are abnormally prominent.

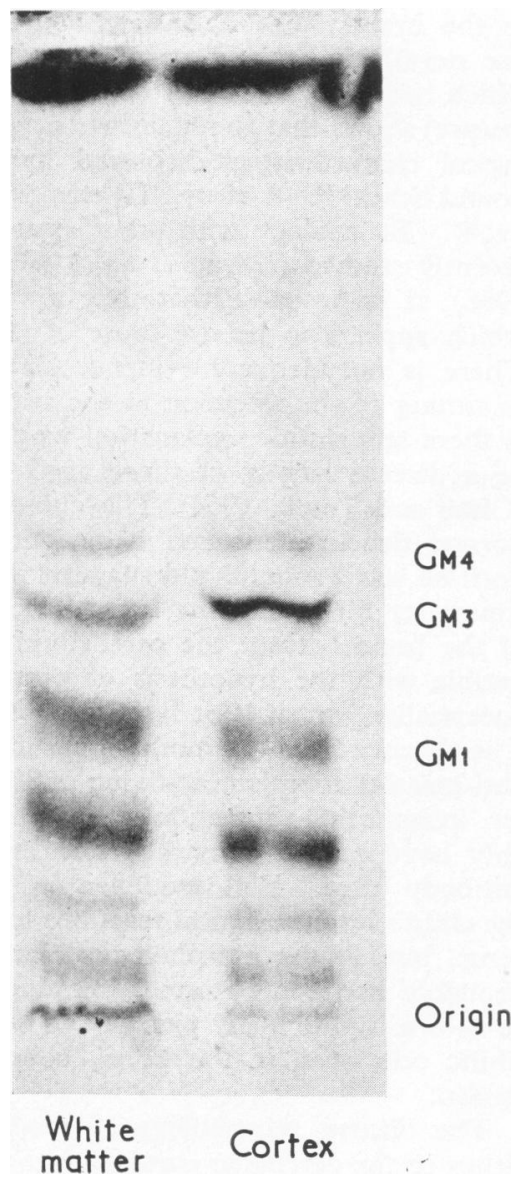


TABLE

Analysis of Cerebral Lipids (g./100 g. dry tissue)

\begin{tabular}{|c|c|c|c|c|c|}
\hline & & \multicolumn{2}{|c|}{ Patient } & \multicolumn{2}{|c|}{ Normal } \\
\hline & & White & Cortex & White & Cortex \\
\hline $\begin{array}{l}\text { Total phospholipids } \\
\text { Total cholesterol ... } \\
\text { Esterified cholesterol } \\
\text { Total cerebrosides } \\
\text { Total hexosamine . . } \\
\text { N-acetyl neuraminic acid } \\
\text { Water }(\%) \text {. . . }\end{array}$ & $\begin{array}{l}\cdots \\
\cdots \\
\cdots \\
\cdots \\
\cdots \\
\cdots\end{array}$ & $\begin{array}{l}19 \cdot 85 \\
5 \cdot 8 \\
0 \cdot 6 \\
2 \cdot 7 \\
0 \cdot 5 \\
0 \cdot 3 \\
85 \cdot 9\end{array}$ & $\begin{array}{l}21 \cdot 9 \\
5 \cdot 2 \\
0 \cdot 4 \\
2 \cdot 4 \\
0 \cdot 55 \\
0 \cdot 3 \\
87 \cdot 3\end{array}$ & $\begin{array}{r}25 \cdot 5 \\
7 \cdot 8 \\
0 \cdot 4 \\
8 \cdot 8 \\
0 \cdot 4 \\
0 \cdot 1 \\
80 \cdot 3\end{array}$ & $\begin{array}{r}23 \cdot 2 \\
5 \cdot 1 \\
0 \cdot 2 \\
3 \cdot 0 \\
0 \cdot 8 \\
0 \cdot 3 \\
82 \cdot 3\end{array}$ \\
\hline
\end{tabular}

in any previously reported case of SSPE. Even in the Antwerp series of 75 cases reviewed by Canal and Torck (1964), the youngest patient was 3 years old at the onset of the disease.

Further evidence that the child had SSPE comes from the thin section electron micrographs of virus-like helical filaments in parenchymal cells in the brain. The helical structure displayed in the negatively stained preparations (examples of which have not previously been obtained from this disease) shows that the filaments have the morphological characteristics displayed by certain compound helical RNA viruses (Waterson and Almeida, 1966). By analogy with other examples of SSPE recently studied (Dayan et al., 1967; Symposium, 1968), it is probable that they are measles virus which appears to be the cause of classical SSPE. There is no adequate evidence about the source or timing of the infection in the present case, nor is there any simple explanation why SSPE should be a disease largely of those aged 5 to 20 years (Canal and Torck, 1964). The clinical evidence of normal development and behaviour of the child until he was 2 months old suggests infection sometime after birth, and the over-all normal anatomy of the brain (except the cerebellum) is also compatible with the hypothesis of postnatal onset of encephalitis, or, at least late intrauterine infection. The absence from the mother's serum of detectable anti-measles complement-fixing antibody is against an intrauterine infection, which would probably have caused a marked rise in the maternal antibody titre. Full evidence is lacking about the child's immunological reactions to the presumed virus, but, at the morphological level at least, he probably had some normal immune mechanisms, as shown by the many plasma and other pyroninophilic cells seen in the brain, bone-marrow, and spleen.

The bizarre morphology of Purkinje cell dendrites in the cerebellar cortex, which also seems not to have been recorded previously in SSPE, could have resulted from any of four causes. Firstly, they might be due to congenital dysplasia, though this seems unlikely because of the patchy nature of the lesion, its striking differences from other congenital cerebellar atrophies (Norman, 1963), and because it would mean that the child had two independent illnesses. Secondly, it could have been caused by viral infection of Purkinje cells: none of the available morphological evidence can prove or disprove this in terms of the absence of inclusion bodies from Purkinje cells and the lack of inflammatory lesions from the cerebellum, though there was diffuse gliosis of its white matter. If the lesions were due to the virus it would be a good example of permanent morphological change less than cell death, produced by chronic viral infection of susceptible cells. The dendritic abnormalities of the Purkinje cells bear some resemblance to those observed in divers lipidoses (Norman, 1963), and could perhaps be due to the effect of the abnormal pattern of gangliosides found in the brain. Comparable changes were not recorded in the other cases of SSPE with similar chemical lesions (Norton et al., 1966; Ledeen et al., 1968), though the appropriate staining methods for displaying Purkinje cell dendrites were not employed. In the present case, unlike a classical lipidosis, there was no over-all excess of gangliosides in the brain. As we do not know whether Purkinje cell lesions in lipidoses are due directly to an effect of the intracellular excess of these compounds, or to an altered growth pattern of the cells caused by the disordered metabolic pathway, this hypothesis remains untested for the present. Lastly, the Purkinje cell changes could be interpreted as a reaction to damage produced by the encephalitis of the sort called by Bouman (1934) 'hyperdifferentiation', and here due to cell development disturbed by a lack of the normal exogenous controlling influences destoyed by the infection. Such an effect in the present case would suggest antenatal onset of the brain damage.

The biochemical abnormalities in the brain appear to be unique like many of its other features. Various abnormalities in lipid composition of the brain of older patients with SSPE have been recorded (Cumings, 1960; Szliwowski and Cumings 1961), mainly taking the form of increases in esterified cholesterol due to demyelination, and in hexosamine, either in the lipid soluble or insoluble residue fractions. Thin-layer chromatography (TLC) studies of SSPE brains have only recently been reported by Norton et al. (1966) and Ledeen et al. (1968); and those two cases, though resem- 
bling each other, both differ from the present findings. Both previous reports described increased amounts in the brain of the monosialogangliosides $\mathrm{G}_{\mathrm{M} 2}$ and $\mathrm{G}_{\mathrm{M} 3}$. Norton et al. found an over-all twofold increase in total ganglioside concentration, with abnormalities restricted to the white matter. Ledeen et al. illustrate raised levels also of the disialo-gangliosides $\mathrm{G}_{3 \mathrm{~A}}$ and $\mathrm{G}_{2 \mathrm{~A}}$ (in their Korey nomenclature). Our case showed an increase in $G_{3 A}\left(G_{D 3}\right.$ in the Svennerholm terminology used here) but not in $G_{2 A}$. All these compounds may occasionally be present in small amounts in normal brains. Their occurrence in much greater concentration in SSPE (though still not in the marked excess over normal of one type of ganglioside found classically in lipidoses such as Tay-Sachs' disease) might be an effect of the inflammation, or due to the virus perhaps causing a continuing metabolic perversion of infected cells. Both Norton et al. and Ledeen et al. suggested that the changes they found were due to inflammation, but their hypothesis fails to explain why they do not always occur, e.g. the case referred to briefly by Dayan et al. (1967) was analysed by the same methods, and did not show any abnormality of gangliosides on TLC. It is possible that this is an example of a virus-induced alteration in ganglioside metabolism, rather than an expression of the ganglioside composition of the increased numbers of glial cells in the damaged brain, as suggested by Ledeen et al. In our case the absence of abnormal gangliosides from the frozen viscera affords evidence against a possible congenital metabolic defect as the cause of the chemical lesion, because, in proven instances of such inherited enzymatic disorders, e.g. Tay-Sachs' disease, the viscera are also involved (Eeg-Olofsson et al., 1966). In two other cases (not of SSPE) in which we found similar but not identical chemical abnormalities (Dayan and Cumings, in preparation), and where the history suggested an inherited metabolic lesion, visceral storage of the gangliosides had occurred. The finding of abnormal gangliosides in peripheral nerve, albeit in trace amounts only, is possibly due to centrifugal carriage of the compounds from the central nervous system by axoplasmic flow. The presence of an approximately normal total amount of gangliosides in the brain accounts for the inability of histochemical techniques to demonstrate any specific lesion.

At present SSPE is one of the very few disorders the probable cause of which has been identified as a known virus behaving in a temperate fashion (Symposium, 1968). It seems intriguing that from the evidence of the present case at least, it may also be one of the first human disorders in which may be seen persistent and specific structural and metabolic lesions other than death of cells chronically infected by the virus.

\section{Summary}

A 5-month-old boy died after a short neurological illness. Histological and electron microscope studies on necropsy samples of brain showed that he had subacute sclerosing panencephalitis, and that there were measles virus-like filaments in parenchymal cells of the brain. There were bizarre abnormalities of Purkinje cell dendrites in the cerebellum.

Biochemical analysis of the brain showed an abnormal pattern of gangliosides in both cortex and white matter, with a relative excess of $G_{M 3}$ and $G_{M 4}$.

It is suggested that the temperate viral infection caused both the morphological and the biochemical lesions.

We are grateful to Dr. D. A. J. Williamson for permission to study the patient and to Dr. I. N. L. Johnson for information about the family. We thank Mrs. J. D. Almeida and Dr. M. A. Woodhouse for electron microscope studies, Dr. J. V. T. Gostling for the serological study, Professor $\mathrm{H}$. Urich and the late Dr. R. M. Norman for advice, and Mrs. M. Blackman, Miss M. I. Stokes, and Messrs. H. Goodwin, R. H. Hunt, and $\mathrm{J}$. Mitchell for skilled assistance.

\section{REFERENCES}

Bouman, L. (1934). Senile plaques. Brain, 57, 128.

Canal, N., and Torck, P. (1964). An epidemiological study of sub-acute sclerosing leucoencephalitis in Belgium. $\mathcal{f}$. neurol. Sci., 1, 380.

Cumings, J. N. (1960). The diagnostic value of biochemical examination of cerebral biopsy material Psychiat. Neurol. Neurochir. (Amst.), 63, 110.

- (1965). Cerebral lipid biochemistry in the demyelinations. In Biochemical Aspects of Neurological Disorders. Second Series, p. 299 . Ed. by J. N. Cumings and M. Kremer. Blackwell, Oxford.

—, and Rozdilsky, B. (1965). The cerebral lipid composition of the brain in six cases of Krabbes disease. Neurology (Minneap.), 15, 177.

Dayan, A. D., Gostling, J. V. T., Greaves, J. L., Stevens, D. W., and Woodhouse, M. A. (1967). Evidence of a psuedomyxovirus in the brain in subacute sclerosing leucoencephalitis. Lancet, 1, 980.

Eeg-Olofsson, O., Kristensson, K., Sourander, P., and Svennerholm, L. (1966). Tay-Sach's disease: a generalized metabolic disorder. Acta paediat. scand., 55, 546.

Folch, J., Lees, M., and Sloane Stanley, G. H. (1957). A simple method for the isolation and purification of total lipides from animal tissue. F. biol. Chem., 226, 497.

Greenfield, J. G. (1963). Infectious diseases of the central nervous system. In Greenfield's Neuropathology, 2nd ed., p. 206. Ed. by W. Blackwood, W. H. McMenemey, A. Meyer, R. M. Norman, and D. S. Russell. Arnold, London.

Ledeen, R., Salsman, K., and Cabrera, M. (1968). Gangliosides in subacute sclerosing leukoencephalitis. F. Lipid Res., 8, 129. 
Müldner, H. G., Wherrett, J. R., and Cumings, J. N. (1962) Some applications of thin-layer chromatography in the study of cerebral lipids. F. Neurochem., 9, 607.

Norman, R. M. (1963). Tay-Sach's disease. In Greenfield's Neuropathology, 2nd ed., p. 416. Ed. by W. Blackwood, W. H. McMenemey, A. Meyer, R. M. Norman, and D. S. Russell. Arnold, London.

Norton, W. T., Poduslo, S. E., and Suzuki, K. (1966). Subacute sclerosing leukoencephalitis. II. Chemical studies including abnormal myelin and an abnormal ganglioside pattern. $\mathcal{f}$. Neuropath. exp. Neurol., 25, 582.

Osetowska, E. (1961). The distribution of telencephalic lesions in subacute sclerosing leukoencephalitis. In Encephalitides, p. 414. Ed by L. van Bogaert, J. Radermecker, J. Hozay, and A. Lowenthal. Elsevier, London.
Radin, N. S., Brown, J. R., and Lavin, F. B. (1956). The preparative isolation of cerebrosides. F. biol. Chem., 219, 977.

Svennerholm, L. (1956). The quantitative, estimation of cerebrosides in nervous tissue. $f$. Neurochem., 1, 42.

Symposium (1968). Measles virus and subacute sclerosing panencephalitis. Neurology (Minneap.), 18, no. 1, pt. 2.

Szliwowski, H. B., and Cumings, J. N. (1961). Les lipides cérébraux dans l'encéphalite subaiguë. Acta neurol. belg., 61, 153.

Waterson, A. P., and Almeida, J. D. (1966). Taxonomicimplication of 'myxovirus'. Nature (Lond.), 210, 1138.

Correspondence to Dr. A. D. Dayan, Department of Neuropathology, The Hospital for Sick Children, Great Ormond Street, London W.C.1. 